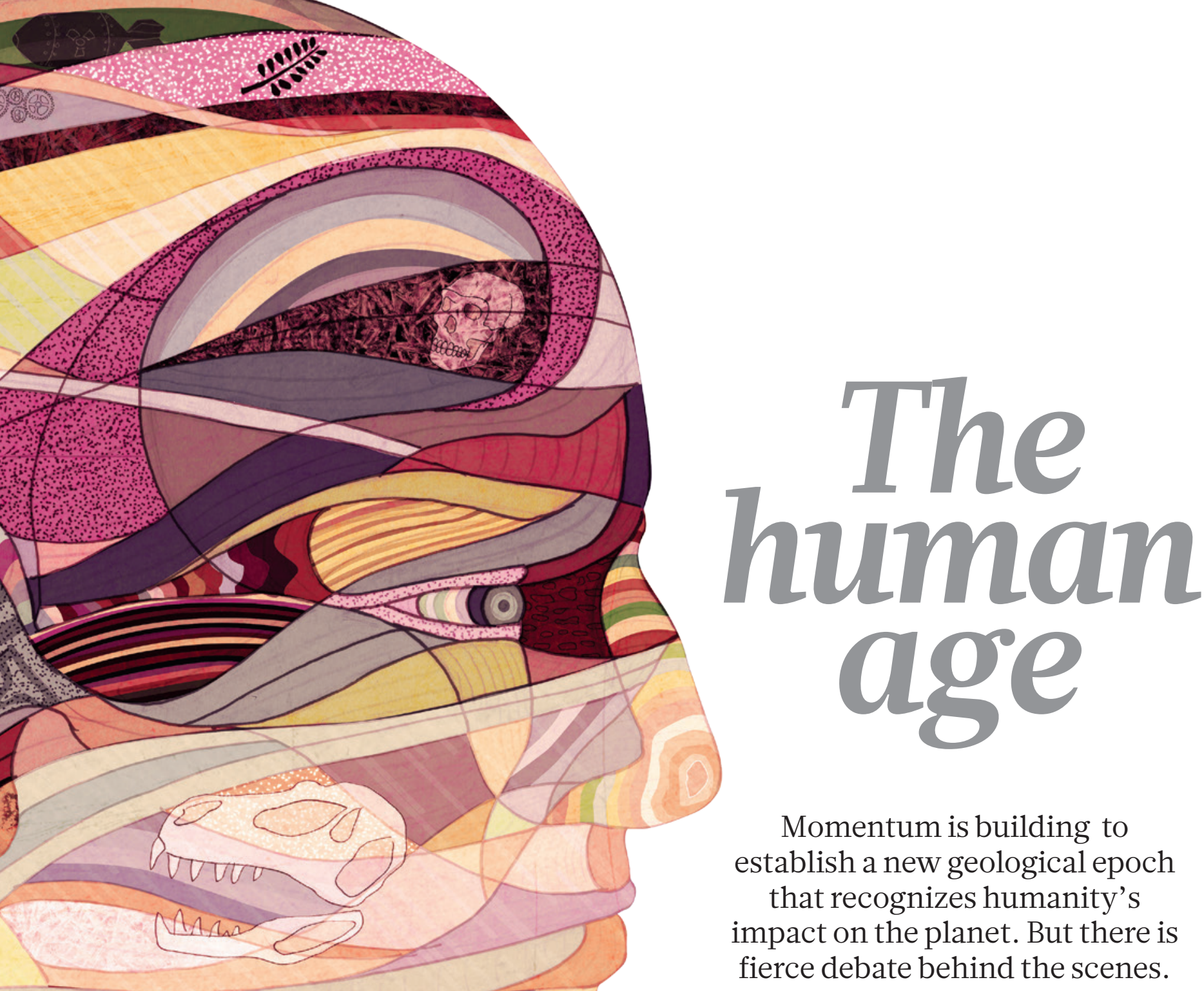

BY RICHARD MONASTERSKY

A

Wing is part of a team carrying out a radical, US\$45-million redesign of the exhibition space, which is part of the Smithsonian Institution. And when it opens again in 2019, the hall will do more than revisit Earth's distant past. Alongside the typical displays of Tyrannosaurus rex and Triceratops, there will be a new section that forces visitors to consider the species that is currently dominating the planet.

"We want to help people imagine their role in the world, which is maybe more important than many of them realize," says Wing.

This provocative exhibit will focus on the Anthropocene - the slice of Earth's history during which people have become a major geological force. Through mining activities alone, humans move more sediment than all the world's rivers combined. Homo sapiens has also warmed the planet, raised sea levels, eroded the ozone layer and acidified the oceans.

Given the magnitude of these changes, many researchers propose that the Anthropocene represents a new division of geological time. The concept has gained traction, especially in the past few years - and not just among geoscientists. The word has been invoked by archaeologists, historians and even gender-studies researchers; several museums 
around the world have exhibited art inspired by the Anthropocene; and the media have heartily adopted the idea. "Welcome to the Anthropocene," The Economist announced in 2011.

The greeting was a tad premature. Although the term is trending, the Anthropocene is still an amorphous notion - an unofficial name that has yet to be accepted as part of the geological timescale. That may change soon. A committee of researchers is currently hashing out whether to codify the Anthropocene as a formal geological unit, and when to define its starting point.

But critics worry that important arguments against the proposal have been drowned out by popular enthusiasm, driven in part by environmentally minded researchers who want to highlight how destructive humans have become. Some supporters of the Anthropocene idea have even been likened to zealots. "There's a similarity to certain religious groups who are extremely keen on their religion - to the extent that they think everybody who doesn't practise their religion is some kind of barbarian," says one geologist who asked not to be named.

The debate has shone a spotlight on the typically unnoticed process by which geologists carve up Earth's 4.5 billion years of history. Normally, decisions about the geological timescale are made solely on the basis of stratigraphy — the evidence contained in layers of rock, ocean sediments, ice cores and other geological deposits.

But the issue of the Anthropocene "is an order of magnitude more complicated than the stratigraphy", says Jan Zalasiewicz, a geologist at the University of Leicester, UK, and the chair of the Anthropocene Working Group that is evaluating the issue for the International Commission on Stratigraphy (ICS).

\section{WRITTEN IN STONE}

For geoscientists, the timescale of Earth's history rivals the periodic table in terms of scientific importance. It has taken centuries of painstaking stratigraphic work - matching up major rock units around the world and placing them in order of formation - to provide an organizing scaffold that supports all studies of the planet's past. "The geologic timescale, in my view, is one of the great achievements of humanity," says Michael Walker, a Quaternary scientist at the University of Wales Trinity St David in Lampeter, UK.

Walker's work sits at the top of the timescale. He led a group that helped to define the most recent unit of geological time, the Holocene epoch, which began about 11,700 years ago.

The decision to formalize the Holocene in 2008 was one of the most recent major actions by the ICS, which oversees the timescale. The commission has segmented Earth's history into a series of nested blocks, much like the years, months and days of a calendar. In geological time, the 66 million years since the death of the dinosaurs is known as the Cenozoic era. Within that, the Quaternary period occupies the past 2.58 million years - during which Earth has cycled in and out of a few dozen ice ages. The vast bulk of the Quaternary consists of the Pleistocene epoch, with the Holocene occupying the thin sliver of time since the end of the last ice age.

When Walker and his group defined the beginning of the Holocene, they had to pick a spot on the planet that had a signal to mark that boundary. Most geological units are identified by a specific change recorded in rocks - often the first appearance of a ubiquitous fossil. But the Holocene is so young, geologically speaking, that it permits an unusual level of precision. Walker and his colleagues selected a climatic change - the end of the last ice age's final cold snap - and identified a chemical signature of that warming at a depth of $1,492.45$ metres in a core of ice drilled near the centre of Greenland ${ }^{1}$. A similar fingerprint of warming can be seen in lake
DNATURE.COM To hear more about the Anthropocene, visit:

go.nature.com/vybhfu and marine sediments around the world, allowing geologists to precisely identify the start of the Holocene elsewhere.

Even as the ICS was finalizing its decision on the start of the Holocene, discussion was already building about whether it was time to end that epoch and replace it with the Anthropocene. This idea has a long history. In the mid-nineteenth century, several geologists sought to recognize the growing power of humankind by referring to the present as the 'anthropozoic era', and others have since made similar proposals, sometimes with different names. The idea has gained traction only in the past few years, however, in part because of rapid changes in the environment, as well as the influence of Paul Crutzen, a chemist at the Max Plank Institute for Chemistry in Mainz, Germany.

Crutzen has first-hand experience of how human actions are altering the planet. In the 1970s and 1980s, he made major discoveries about the ozone layer and how pollution from humans could damage it - work that eventually earned him a share of a Nobel prize. In 2000, he and Eugene Stoermer of the University of Michigan in Ann Arbor argued that the global population has gained so much influence over planetary processes that the current geological epoch should be called the Anthropocene $e^{2}$. As an atmospheric chemist, Crutzen was not part of the community that adjudicates changes to the geological timescale. But the idea inspired many geologists, particularly Zalasiewicz and other members of the Geological Society of London. In 2008, they wrote a position paper urging their community to consider the idea ${ }^{3}$.

Those authors had the power to make things happen. Zalasiewicz happened to be a member of the Quaternary subcommission of the ICS, the body that would be responsible for officially considering the suggestion. One of his co-authors, geologist Phil Gibbard of the University of Cambridge, UK, chaired the subcommission at the time.

Although sceptical of the idea, Gibbard says, "I could see it was important, something we should not be turning our backs on." The next year, he tasked Zalasiewicz with forming the Anthropocene Working Group to look into the matter.

\section{A NEW BEGINNING}

Since then, the working group has been busy. It has published two large reports ("They would each hurt you if they dropped on your toe," says Zalasiewicz) and dozens of other papers.

The group has several issues to tackle: whether it makes sense to establish the Anthropocene as a formal part of the geological timescale; when to start it; and what status it should have in the hierarchy of the geological time - if it is adopted.

When Crutzen proposed the term Anthropocene, he gave it the suffix appropriate for an epoch and argued for a starting date in the late eighteenth century, at the beginning of the Industrial Revolution. Between then and the start of the new millennium, he noted, humans had chewed a hole in the ozone layer over Antarctica, doubled the amount of methane in the atmosphere and driven up carbon dioxide concentrations by $30 \%$, to a level not seen in 400,000 years.

When the Anthropocene Working Group started investigating, it compiled a much longer long list of the changes wrought by humans. Agriculture, construction and the damming of rivers is stripping away sediment at least ten times as fast as the natural forces of erosion. Along some coastlines, the flood of nutrients from fertilizers has created oxygen-poor 'dead zones', and the extra $\mathrm{CO}_{2}$ from fossil-fuel burning has acidified the surface waters of the ocean by $0.1 \mathrm{pH}$ units. The fingerprint of humans is clear in global temperatures, the rate of species extinctions and the loss of Arctic ice.

The group, which includes Crutzen, initially leaned towards his idea of choosing the Industrial Revolution as the beginning of the 


\section{- Mid-twentieth century

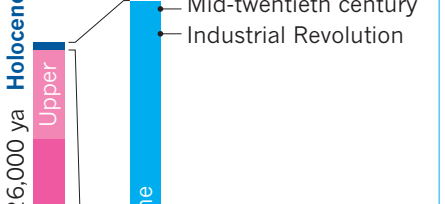 \\ LATE- \\ ANTHROPOCENE PROPOSAL \\ Human impacts on the environment surged in the \\ mid-twentieth century, a trend visible in many records. That time has been called the Great Acceleration.}

The Anthropocene could be added as a new epoch on top of the Holocene. Or the timescale could remain unchanged, in which case the Anthropocene would function as an informal time unit.

$-5,000-7,000$ ya

Expansion in agriculture
Radioactive fallout from nuclear blasts peaked in the

mid-twentieth century, leaving a signal visible in sediments that has been proposed as a marker for the start of the Anthropocene.

\section{Humans at the helm}

Researchers are studying whether the geological timescale should be modified to include the Anthropocene, a unit of time during which humans became a major force on the planet. Some support starting the Anthropocene in the mid-twentieth century, whereas others propose much earlier dates.

LARGE DAMS
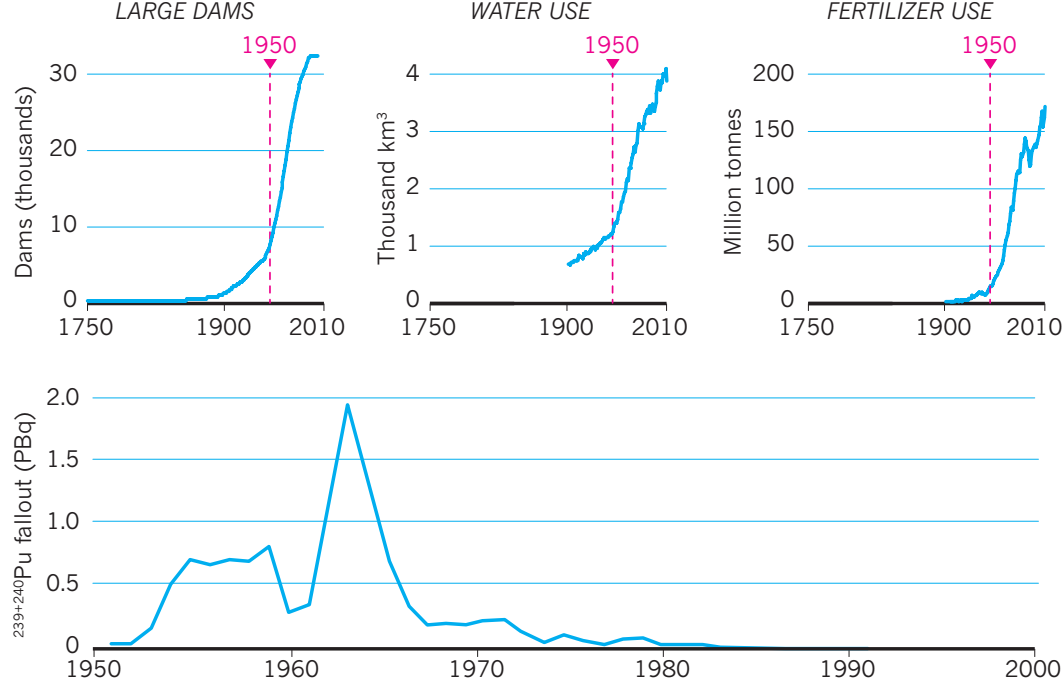

EARLYANTHROPOCENE PROPOSAL

Humans began transforming the land surface thousands of years ago, through agriculture and other activities. That has led some researchers to propose an early start date for the Anthropocene.

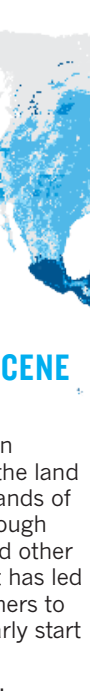

One potential stratigraphic marker is a rise in the atmospheric concentration of methane millennia ago, which is recorded in glacial ice. This could reflect increases in farming and animal herding.

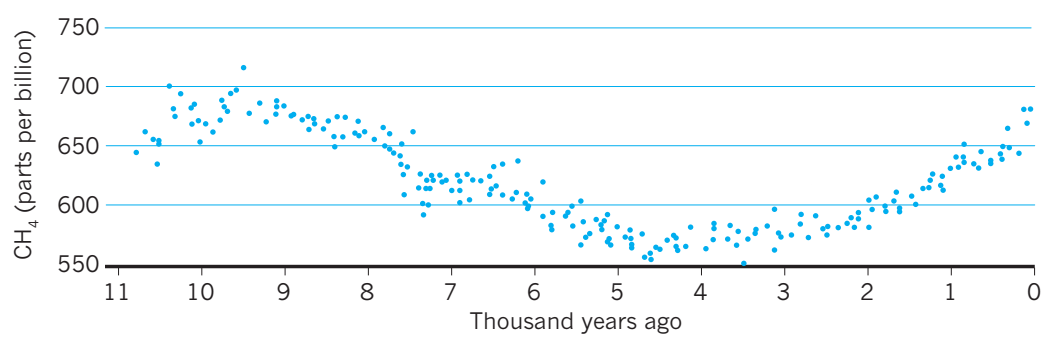

Anthropocene. But other options were on the table.

Some researchers have argued for a starting time that coincides with an expansion of agriculture and livestock cultivation more than 5,000 years ago ${ }^{4}$, or a surge in mining more than 3,000 years ago (see 'Humans at the helm'). But neither the Industrial Revolution nor those earlier changes have left unambiguous geological signals of human activity that are synchronous around the globe.

This week in Nature, two researchers propose that a potential marker for the start of the Anthropocene could be a noticeable drop in atmospheric $\mathrm{CO}_{2}$ concentrations between 1570 and 1620, which is recorded in ice cores (see page 171). They link this change to the deaths of some 50 million indigenous people in the Americas, triggered by the arrival of Europeans. In the aftermath, forests took over 65 million hectares of abandoned agricultural fields - a surge of regrowth that reduced global $\mathrm{CO}_{2}$.

In the working group, Zalasiewicz and others have been talking increasingly about another option — using the geological marks left 
by the atomic age. Between 1945 and 1963, when the Limited Nuclear Test Ban Treaty took effect, nations conducted some 500 above-ground nuclear blasts. Debris from those explosions circled the globe and created an identifiable layer of radioactive elements in sediments. At the same time, humans were making geological impressions in a number of other ways - all part of what has been called the Great Acceleration of the modern world. Plastics started flooding the environment, along with aluminium, artificial fertilizers, concrete and leaded petrol, all of which have left signals in the sedimentary record.

In January, the majority of the 37-person working group offered its first tentative conclusion. Zalasiewicz and 25 other members reported ${ }^{5}$ that the geological markers available from the mid-twentieth century make this time "stratigraphically optimal" for picking the start of the Anthropocene, whether or not it is formally defined. Zalasiewicz calls it "a candidate for the least-worst boundary".

The group even proposed a precise date: 16 July 1945 , the day of the first atomic-bomb blast. Geologists thousands of years in the future would be able to identify the boundary by looking in the sediments for the signature of long-lived plutonium from mid-century bomb blasts or many of the other global markers from that time.

\section{A MANY-LAYERED DEBATE}

The push to formalize the Anthropocene upsets some stratigraphers. In 2012, a commentary published by the Geological Society of America ${ }^{6}$ asked: "Is the Anthropocene an issue of stratigraphy or pop culture?" Some complain that the working group has generated a stream of publicity in support of the concept. "I'm frustrated because any time they do anything, there are newspaper articles," says Stan Finney, a stratigraphic palaeontologist at California State University in Long Beach and the chair of the ICS, which would eventually vote on any proposal put forward by the working group. "What you see here is, it's become a political statement. That's what so many people want."

Finney laid out some of his concerns in a paper ${ }^{7}$ published in 2013. One major question is whether there really are significant records of the Anthropocene in global stratigraphy. In the deep sea, he notes, the layer of sediments representing the past 70 years would be thinner than 1 millimetre. An even larger issue, he says, is whether it is appropriate to name something that exists mainly in the present and the future as part of the geological timescale.

Some researchers argue that it is too soon to make a decision - it will take centuries or longer to know what lasting impact humans are having on the planet. One member of the working group, Erle Ellis, a geographer at the University of Maryland, Baltimore County, says that he raised the idea of holding off with fellow members of the group. "We should set a time, perhaps 1,000 years from now, in which we would officially investigate this," he says. "Making a decision before that would be premature."

That does not seem likely, given that the working group plans to present initial recommendations by 2016 .

Some members with different views from the majority have dropped out of the discussion. Walker and others contend that human activities have already been recognized in the geological timescale: the only difference between the current warm period, the Holocene, and all the interglacial times during the Pleistocene is the presence of human societies in the modern one. "You've played the human card in defining the Holocene. It's very difficult to play the human card again," he says.

Walker resigned from the group a year ago, when it became clear that he had little to add. He has nothing but respect for its members, he says, but he has heard concern that the Anthropocene movement is picking up speed. "There's a sense in some quarters that this is something of a juggernaut," he says. "Within the geologic community, particularly within the stratigraphic community, there is a sense of disquiet."
Zalasiewicz takes pains to make it clear that the working group has not yet reached any firm conclusions. "We need to discuss the utility of the Anthropocene. If one is to formalize it, who would that help, and to whom it might be a nuisance?" he says. "There is lots of work still to do."

Any proposal that the group did make would still need to pass a series of hurdles. First, it would need to receive a supermajority - $60 \%$ support - in a vote by members of the Quaternary subcommission. Then it would need to reach the same margin in a second vote by the leadership of the full ICS, which includes chairs from groups that study the major time blocks. Finally, the executive committee of the International Union of Geological Sciences must approve the request.

At each step, proposals are often sent back for revision, and they sometimes die altogether. It is an inherently conservative process, says Martin Head, a marine stratigrapher at Brock University in St Catharines, Canada, and the current head of the Quaternary subcommission. "You are messing around with a timescale that is used by millions of people around the world. So if you're making changes, they have to be made on the basis of something for which there is overwhelming support."

Some voting members of the Quaternary subcommission have told Nature that they have not been persuaded by the arguments raised so far in favour of the Anthropocene. Gibbard, a friend of Zalasiewicz's, says that defining this new epoch will not help most Quaternary geologists, especially those working in the Holocene, because they tend not to study material from the past few decades or centuries. But, he adds: "I don't want to be the person who ruins the party, because a lot of useful stuff is coming out as a consequence of people thinking about this in a systematic way."

If a proposal does not pass, researchers could continue to use the name Anthropocene on an informal basis, in much the same way as archaeological terms such as the Neolithic era and the Bronze Age are used today. Regardless of the outcome, the Anthropocene has already taken on a life of its own. Three Anthropocene journals have started up in the past two years, and the number of papers on the topic is rising sharply, with more than 200 published in 2014.

By 2019, when the new fossil hall opens at the Smithsonian's natural history museum, it will probably be clear whether the Anthropocene exhibition depicts an official time unit or not. Wing, a member of the working group, says that he does not want the stratigraphic debate to overshadow the bigger issues. "There is certainly a broader point about human effects on Earth systems, which is way more important and also more scientifically interesting."

As he walks through the closed palaeontology hall, he points out how much work has yet to be done to refashion the exhibits and modernize the museum, which opened more than a century ago. A hundred years is a heartbeat to a geologist. But in that span, the human population has more than tripled. Wing wants museum visitors to think, however briefly, about the planetary power that people now wield, and how that fits into the context of Earth's history. "If you look back from 10 million years in the future," he says, "you'll be able to see what we were doing today." - SEE EDITORIAL P.129

\section{Richard Monastersky is a features editor for Nature in} Washington DC.

\section{Walker, M. et al. J. Quat. Sci. 24, 3-17 (2009)}

2. Crutzen, P. J. \& Stoermer, E. F. IGBP Newsletter 41, 17-18 (2000)

3. Zalasiewicz. J. et al. GSA Today 18(2), 4-8 (2008).

4. Ruddiman, W. F. Ann. Rev. Earth. Planet. Sci. 41, 45-68 (2013)

5. Zalasiewicz, J. et al. Quatern. Int. http://dx.doi.org/10.1016/j.quaint.2014.11.045 (2015)

6. Autin, W. J. \& Holbrook, J. M. GSA Today 22(7), 60-61 (2012).

7. Finney, S. C. Geol. Soc. Spec. Publ. 395, 23-28 (2013). 